\title{
GGE Biplot Analysis of 12 Dioscorea rotundata Genotypes in Ghana
}

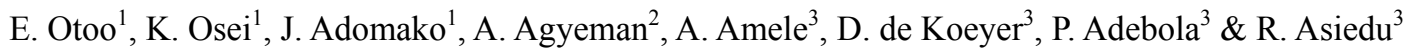 \\ ${ }^{1}$ CSIR-Crops Research Institute, Kumasi, Ghana \\ ${ }^{2}$ CSIR-Science and Technology Policy Research Institute, Accra, Ghana \\ ${ }^{3}$ International Institute for Tropical Agriculture, Ibadan, Nigeria \\ Correspondence: E. Otoo, CSIR-Crops Research Institute, P.O. Box 3785, Kumasi, Ghana. E-mail: \\ otooemmanuel@gmail.com
}

Received: September 26, 2017

Accepted: November 4, 2017 Online Published: December 15, 2017

doi:10.5539/jas.v10n1p249

URL: https://doi.org/10.5539/jas.v10n1p249

\begin{abstract}
To determine the effects of environment and genotypic differences on tuber yield and other related traits, 12 genotypes comprising 9 improved elite clones, two local landraces and 1 improved and released variety were evaluated for tuber yield, response to yam mosaic virus and leaf spot diseases at 16 growing environments. The multi-environment trials were conducted using randomized complete-block design with three blocks for four years in four representative agro-ecological zones (Atebubu, Kintampo, Ejura and Fumesua) in Ghana. The objective was to select high and stable yielding varieties for release as varieties in Ghana. The multi-environment data for the trials collected were subjected to combine analyses of variance using the ANOVA procedure of Statistical Tool for Agricultural Research (STAR) to determine the magnitude of the main effects and interactions. Genotype main effect and genotype by environment interaction effect (GGE) model was used to dissect the genotype by environment interaction (GEI) using the GGE biplot software (GGE biplot, 2007). GGE biplots analysis was applied for visual examination of the GEI pattern in the data set. A highly significant effects $(\mathrm{P}<$ 0.001) for Genotype (G), environment (E) and genotype by environment (GEI) interaction were occurred in the data set for highly significant for all the traits studied $(\mathrm{P}<0.001)$, indicating genetic variability between genotypes by changing environments. This indicated changes in ranking order of the genotype performances across the test environments. The partitioning of the GGE effect for tuber yield through in GGE biplot analysis model showed that PC1 and PC2 accounted for $40.47 .0 \%$ and $19.89 .0 \%$ of the variation GGE sum of squares respectively for tuber yield, respectively explaining a total of $60.36 \%$ variation. Mankrong Pona was the most stable and high yielding (closest to the ideal genotype) followed by TDr95/19177. Genotypes TDr00/02472, TDr00/00539 and TDr98/00933 are desirable genotypes for further assessment on culinary characteristics and end-user assessment for release as varieties. All the four locations used for the study were highly relevant for research and development of yams. Ejura and Fumesua were the most discriminating and most representative for YMV respectively. In terms of yield, Kintampo environment was the most discriminating and Fumesua and Atebubu were the closest to ideal environment for evaluating yield.
\end{abstract}

Keywords: Dioscorea, environment, genotype, Ghana, location, stability, yams

\section{Introduction}

Yam, (Dioscorea spp.) is an important food crop in Ghana. It is the most important and prestigious staple food as well as the food of choice at many ceremonies and festivals. The importance of yams in the sub-region cannot therefore be over-emphasized. Ghana comes third after Nigeria and Cote d'ivoire in terms of production. Ghana, however, is the leading exporter of yams. Ghana has a comparative advantage in yam production; yam production in Ghana has witnessed consistently high productivity over Nigeria, over the past decade. Of about 600 known yam species, only about six are important as staples in the tropics namely: $D$. rotundata, $D$. cayenensis, $D$. alata, $D$. dumetorum, $D$. bulbifera and $D$. esculenta. Together they account for $90 \%$ of all yams grown in Ghana. In Ghana, $D$. rotundata is the most widely cultivated yam species followed by $D$. alata, and then $D$. cayenensis Poir. $D$. rotundata and $D$. cayenensis lam (both known as Guinea yams) are the most yams and are indigenous to West and Central Africa.

Work done on genotype $\times$ environment interactions (GEI) in some economic crops include yam (Otoo \& Asiedu, 2009a, 2009b) and cassava (Akinyele \& Osekita, 2011; Sakin et al., 2011) among others and all confirming that 
the phenotype of an individual is determined by both the genotype and the environment. The effects of these two factors, however, are not always additive because of the interaction between them. The large GEI variation usually impairs the accuracy of yield estimation and reduces the relationship between genotypic and phenotypic values (Ssemakula \& Dixon, 2007). GEI, due to different responses of genotypes in diverse environments, makes choosing the superior genotypes difficult in plant breeding programmes.

Different statistical analyses methods have been developed and applied in many crops for describing, exploring, understanding, and predicting GEI (Malosetti et al., 2013). Genotype main effect plus genotype by environment interaction (GGE) model and the biplots which is called GGE biplots (Yan et al., 2000) is among the methods widely utilized to exploit GEI in many crops. GGE model is based on the understanding that genotype main effect (G) and genotype by environment interaction (GEI) are the two sources of variation that are relevant to genotype evaluation in multi-environment trials and must be considered simultaneously, not alone or separately, for appropriate genotype evaluation (Yan, 2005). This model has been successfully used in evaluating yams in Ghana (Otoo \& Asiedu, 2009a, 2009b).

Traditionally, plant breeders tend to select genotypes that show stable performance as defined by minimal GEI effects across number of locations and/or years. GGE biplot analysis is an effective method, which is based on principal component analysis (PCA) to fully explore multi-environment trials (METs). It allows visual examination of the relationships among the test environments, genotypes and the genotype-by-environment interactions ( $\mathrm{G} \times \mathrm{E}$ interaction). GGE biplot is a data visualization tool, which graphically displays a $\mathrm{G} \times \mathrm{E}$ interaction in a two way table (Yan et al., 2000). GGE biplot is an effective tool for: 1) mega-environment analysis (e.g. "which-won-where" pattern), whereby specific genotypes can be recommended to specific mega-environments (Yan \& Kang, 2003), 2) genotype evaluation (the mean performance and stability), and 3) environmental evaluation (the power to discriminate among genotypes in target environments).

This study therefore, was, designed to evaluate the performance of D. rotundata genotypes grown in multi-environment trials in Ghana for 4 years and identifies suitable clones for release as new varieties for release and production.

\section{Materials and Methods}

The study was conducted from 2013-2016 cropping seasons at four locations in Ghana. The locations are: Atebubu, Kintampo, Ejura and Fumesua in Ghana (Table 1).

Table 1. Characteristics of test sites

\begin{tabular}{|c|c|c|c|c|}
\hline Location & Ejura & Kintampo & Atebubu & Fumesua \\
\hline Agroecology & Forest-Savannah Transition & Forest-Savannah Transition & Forest-Savannah Transition & Forest \\
\hline Coordinates & $7^{\circ} 23^{\prime} \mathrm{N}, 1^{\circ} 21^{\prime} \mathrm{W}$ & $8.0593^{\circ} \mathrm{N}, 1.7296^{\circ} \mathrm{W}$ & $7.7541^{\circ} \mathrm{N}, 0.9845^{\circ} \mathrm{W}$ & $6^{\circ} 41^{\prime} \mathrm{N}, 1^{\circ} 28^{\prime} \mathrm{W}$ \\
\hline Soil Type & $\begin{array}{l}\text { Ferric Lixisol; Ejura series } \\
\text { with } 20-30 \mathrm{~cm} \text { thick top } \\
\text { layer of loam soils. Soils are } \\
\text { dark brown to brown fine } \\
\text { sandy loam }\end{array}$ & Ferralic Cambisol & Haplic Acrisol & $\begin{array}{l}\text { Ferric Acrisol; Asuansi } \\
\text { series upper top soil } \\
\text { consisted of } 5 \mathrm{~cm} \text { greyish } \\
\text { brown sandy loam topsoil } \\
\text { of dark brown gritty clay } \\
\text { loam }\end{array}$ \\
\hline Altitude/m & 254 & 334 & 136 & 257 \\
\hline Wet Season & Bimodal rainfall patterne & Bimodal rainfall patterne & Bimodal rainfall patterne & Bimodal rainfall patterne \\
\hline Major & March-Aug; peak in June & March-July; peak in Jun & March-Aug; peak in June & March-July; peak in Jun \\
\hline Minor & Sept-Nov; peak in Oct & Sept-Nov; peak in Oct & Sept-Nov; peak in Oct & Sept-Nov; peak in Oct \\
\hline $\begin{array}{l}\text { Mean Annual } \\
\text { Rainfall (mm) }\end{array}$ & 1235 & 1345 & 1225 & 1448 \\
\hline $\begin{array}{l}\text { Average annual } \\
\text { temperature }\left({ }^{\circ} \mathrm{C}\right)\end{array}$ & 26.1 & 26.1 & 27.3 & 26.3 \\
\hline Comments & $\begin{array}{l}\text { Ejura has a tropical climate. } \\
\text { The summers here have a } \\
\text { good deal of rainfall, while } \\
\text { the winters have very little. } \\
\text { This climate is considered } \\
\text { to be Aw according to the } \\
\text { Köppen-Geiger climate } \\
\text { classification }\end{array}$ & $\begin{array}{l}\text { Kintampo has a tropical } \\
\text { climate. In winter, there is } \\
\text { much less rainfall in } \\
\text { Kintampo than in summer. } \\
\text { This climate is considered } \\
\text { to be Aw according to the } \\
\text { Köppen-Geiger climate } \\
\text { classification. }\end{array}$ & $\begin{array}{l}\text { The climate here is tropical. } \\
\text { When compared with winter, } \\
\text { the summers have much more } \\
\text { rainfall. The Köppen-Geiger } \\
\text { climate classification is Aw. }\end{array}$ & $\begin{array}{l}\text { Has a tropical climate. } \\
\text { The summers are much } \\
\text { rainier than the winters } \\
\text { in Kumasi. According } \\
\text { to Köppen and Geiger, } \\
\text { this climate is classified } \\
\text { as Aw. }\end{array}$ \\
\hline
\end{tabular}


12 yam genotypes comprising 9 new elite clones introduced from International Institute of Tropical Agriculture (IITA), two landraces were used as local checks and one improved and released variety as standard check (Table 2). The experimental design used was completely randomized block design at each site under rain-fed conditions. The experimental plot consisted of 40 plants in four plant rows for each genotype. The ridges were $1 \mathrm{~m}$ apart, $30 \mathrm{~cm}$ high and $10 \mathrm{~m}$ long. The plants were individually staked with $3 \mathrm{~m}$ long bamboo stakes. Spacing between plants was $1 \mathrm{~m}$, giving a total plant population of 10,000 plants $^{-1} \mathrm{a}^{-1}$. Weeding was manually done when necessary. Data were collected from the inner 18 plants within a plot. Parameters taken at the vegetative stage were vigour, severity of yam mosaic virus (YMV), severity of leaf spot disease. Postharvest assessment was on yield and tuber number. Disease severity scores of YMV and Leafspot were taken at 6 month after planting (MAP) using a scale of 1-5 (1= no symptoms and $5=$ severe damage) according to IITA (1990). At harvest (10MAP), data were collected from the inner 18 plants within a plot for tuber yield, and number of tubers per stand. No significant differences were observed in tuber number per stand and severity of leafspot. Hence only significant parameters such as YMV and yield are presented in this paper.

Table 2. List of genotypes evaluated and code

\begin{tabular}{lll}
\hline Code & Genotypes & NATURE \\
\hline 1 & Dente & LOCAL LANDRACE \\
2 & Miriki & LOCAL LANDRACE \\
3 & Mankrong Pona & RELEASED IMPROVED \\
4 & TDr00/00403 & INTRODUCED FROM IITA \\
5 & TDr00/00539 & INTRODUCED FROM IITA \\
6 & TDr00/02472 & INTRODUCED FROM IITA \\
7 & TDr00/02475 & INTRODUCED FROM IITA \\
8 & TDr07/00362 & INTRODUCED FROM IITA \\
9 & TDr07/02673 & INTRODUCED FROM IITA \\
10 & TDr95/19177 & INTRODUCED FROM IITA \\
11 & TDr98/00933 & INTRODUCED FROM IITA \\
12 & TDr99/02674 & INTRODUCED FROM IITA \\
\hline
\end{tabular}

The data were subjected to combined analyses of variance using the ANOVA procedure of Statistical Tools for Agricultural Research (STAR) to determine the magnitude of the main effects and interactions. The GGE Biplot methodology, which is composed of two concepts, the Biplot concept (Gabriel, 1971) and the GGE concept (Yan et al., 2000), was applied for visual examination of the GEI pattern of data by using GGE-biplot software (GGEbiplot, 2009). The GGE biplot shows the first 2 principal components (PC1 and PC2) derived from subjecting environment centered yield data (Yan et al., 2000). For the analysis, no data was transformed and the model used was Global $(\mathrm{G}+\mathrm{E}+\mathrm{GE})$ and scaling with SD. The model applied was singular value partitioning entry-focused for evaluation of entry and tester or environment focused SVP for tester or environment evaluation and data centering $=$ original tester centered data $(\mathrm{G}+\mathrm{GE})$. The data was scaled with standard deviation for generating environment relationship. For rest analysis, no scale used. The statistical analysis and interpretation of GGE was conducted as per Yan and Kang (2003). The codes for genotypes and environments used for the GGE Biplot analyses are presented in Table 3. 
Table 3. Codes for genotype and environment used in GGE biplot analysis

\begin{tabular}{lllllll}
\hline & \multicolumn{2}{c}{ Environment coding } & & \multicolumn{3}{c}{ Genotype coding } \\
\cline { 1 - 2 } \cline { 5 - 6 } SN & Code & Environment name & SN & Code & Genotype name \\
\hline 1 & A16 & ATEBUBU 2016 & & 1 & TDr00/00403 \\
2 & A15 & ATEBUBU 2015 & & 2 & TDr00/00539 \\
3 & A14 & ATEBUBU 2014 & & 3 & TDr00/02472 \\
4 & A13 & ATEBUBU 2013 & & 4 & 4 & TDr95/19177 \\
5 & K16 & KINTAMPO 2016 & & 5 & 5 & Dente (check1) \\
6 & K15 & KINTAMPO 2015 & & 6 & Mankrong Pona (Check3) \\
7 & K14 & KINTAMPO 2014 & & 7 & 7 & Miriki (check2) \\
8 & K13 & KINTAMPO 2013 & & 8 & TDr00/02475 \\
9 & E16 & EJURA 2016 & & 9 & 9 & TDr07/00362 \\
10 & E15 & EJURA 2015 & & 10 & 10 & TDr07/02673 \\
11 & E14 & EJURA 2014 & & 11 & TDr98/00933 \\
12 & E13 & EJURA 2013 & & 12 & 12 & TDr99/02674 \\
13 & F16 & FUMESUA 2016 & & & \\
14 & F15 & FUMESUA 2015 & & & \\
15 & F14 & FUMESUA 2014 & & & & \\
16 & F13 & FUMESUA 2013 & & & & \\
\hline
\end{tabular}

\section{Results}

The combined analysis of variance across environments (Table 4) showed highly significant $(\mathrm{P}<0.001)$ mean squares (MS) for yam mosaic virus (YMV) disease severity score, and yield for all sources of variation. Environment (E), genotypes (G) and genotype by environment interaction (GEI) showed significant variability (P $<0.001)$ for traits evaluated. The relative magnitude of the main effects and their interactions for YMV as a proportion of the total sum of squares showed that $32.7 \%$ of the severity score variation was attributed to Genotype (G), $7.7 \%$ to Environment (E) and 60\% to GEI (Table 4). Similarly, the proportion of the total variation for tuber yield accounted to G, E and their interaction GEI were $19.1,17.8$ and $63.1 \%$, respectively.

Table 4. ANOVA for YMV severity and yield of 12 D. rotundata genotypes in 16 environments (4 years in 4 locations in Ghana)

\begin{tabular}{|c|c|c|c|c|c|c|c|}
\hline \multirow{2}{*}{ Source } & \multicolumn{4}{|c|}{ YMV } & \multicolumn{3}{|c|}{ YIELD } \\
\hline & DF & SS & MS & Explained Variation (\%) & SS & MS & Explained Variation (\%) \\
\hline Genotypes & 11 & 18 & $1.64 * *$ & 32.7 & $2758 *$ & $250.73^{* *}$ & 19.1 \\
\hline Environment & 15 & 4 & $0.27 *$ & 7.3 & $2569 *$ & $171.27 *$ & 17.8 \\
\hline GxE & 165 & 33 & $0.20 * *$ & 60 & $9104 * *$ & $55.18 * *$ & 63.1 \\
\hline
\end{tabular}

Note. ${ }^{*}$ and $* *=$ Significant at $\mathrm{P}<0.05$ and $\mathrm{P}<0.001$ respectively.

\subsection{Reaction to YMV Disease and Yield}

A highly significant $(\mathrm{P}<0.001)$ variation was observed in both YMV and Yield of the 12 genotypes across the various environments (4 locations in 4 years) (Table 4). Across locations and years, the YMV disease scores ranged from 1.0 to 2.2, with a mean of 1.4. Genotype TDr95/19177 expressed the most severe symptom of 2.2. Genotypes Dente (Check 1), Mankrong Pona (Check 2), Miriki (Check 3), TDr00/00403, TDr00/00539, TDr00/02475, TDr07/00362, TDr98/00933 and TDr99/02674 were symptomless (severity scores of 1.1-1.3) (Table 5). Similarly, tuber yield of the genotypes ranged from $36.4 \mathrm{t} / \mathrm{ha}$ (TDr07/02673) to $49.9 \mathrm{t} / \mathrm{ha}$ (Mankrong Pona) with a mean of $42.8 \mathrm{t} / \mathrm{ha}$. 
Table 5. Mean YMV severity scores of 12 white yam genotypes evaluated at four locations over the four years in Ghana

\begin{tabular}{|c|c|c|c|c|c|c|c|c|c|c|c|}
\hline \multirow{2}{*}{ Code } & \multirow{2}{*}{ Genotype } & \multicolumn{5}{|c|}{ Mean YMV score over years } & \multicolumn{5}{|c|}{ YIELD (t/ha) } \\
\hline & & Atebubu & Kintampo & Ejura & Fumesua & Mean & Atebubu & Kintampo & Ejura & Fumesua & Mean \\
\hline 1 & TDr00/00403 & 1.0 & 1.0 & 1.5 & 1.5 & 1.3 & 43.9 & 42.2 & 40.0 & 34.1 & 40.1 \\
\hline 2 & TDr00/00539 & 1.0 & 1.3 & 1.3 & 1.0 & 1.1 & 43.8 & 39.4 & 46.4 & 40.1 & 42.4 \\
\hline 3 & TDr00/02472 & 1.5 & 1.5 & 1.8 & 1.8 & 1.6 & 46.3 & 45.0 & 47.1 & 39.7 & 44.5 \\
\hline 4 & TDr95/19177 & 2.3 & 1.8 & 2.5 & 2.3 & 2.2 & 48.8 & 46.1 & 47.0 & 44.4 & 46.6 \\
\hline 5 & Dente (check1) & 1.3 & 1.2 & 1.4 & 1.3 & 1.3 & 39.1 & 42.6 & 43.0 & 43.2 & 42.0 \\
\hline 6 & Mankrong Pona (Check3) & 1.5 & 1.7 & 1.3 & 1.3 & 1.5 & 52.4 & 50.9 & 48.4 & 47.8 & 49.9 \\
\hline 7 & Miriki (check2) & 1.0 & 1.2 & 1.0 & 1.2 & 1.1 & 37.7 & 42.4 & 49.6 & 41.2 & 42.7 \\
\hline 8 & TDr00/02475 & 1.3 & 1.3 & 1.0 & 1.8 & 1.3 & 45.2 & 40.6 & 40.3 & 39.3 & 41.4 \\
\hline 9 & TDr07/00362 & 1.5 & 1.3 & 1.3 & 1.3 & 1.3 & 37.2 & 39.3 & 39.4 & 32.3 & 37.0 \\
\hline 10 & TDr07/02673 & 1.8 & 2.0 & 1.5 & 2.0 & 1.8 & 35.7 & 37.1 & 37.3 & 35.7 & 36.4 \\
\hline 11 & TDr98/00933 & 1.0 & 1.3 & 1.3 & 1.3 & 1.2 & 45.0 & 48.8 & 48.0 & 47.7 & 47.4 \\
\hline 12 & TDr99/02674 & 1.0 & 1.0 & 2.0 & 1.0 & 1.3 & 46.6 & 40.3 & 42.5 & 42.1 & 42.9 \\
\hline Mean & & 1.3 & 1.4 & 1.5 & 1.5 & 1.4 & 43.5 & 42.9 & 44.1 & 40.6 & 42.8 \\
\hline SE & & 0.2 & 0.2 & 0.2 & 0.2 & 0.2 & 2.6 & 2.3 & 2.2 & 2.3 & 2.3 \\
\hline
\end{tabular}

The partitioning of GGE through GGE biplot analysis showed that PC1 and PC2 accounted for $35.02 \%$ and $16.58 \%$ of GGE sum of squares respectively for YMV, explaining a total of $53.60 \%$ variation) (Figure 1 and Table 4). For YMV disease response, PC1 is based on disease tolerance or susceptibility. Genotypes that had PC1 scores $>0$ were identified as susceptible and those that had PC1 scores $<0$ were identified as tolerant (Figure 1). PC2 is based on stability. A greater absolute value means less stable and vice versa.

Results from Figure 1, showed that the environments expressed high tolerance and stability to YMV disease except in F16 (Fumesua 2016), where had comparatively low tolerance, and K13 (Kintampo 2013), which had high YMV tolerance but was unstable. The rest of the environments had low absolute scores except E13, which was unstable. Genotypes 1, 3, 4, 5 and 11 showed consistently tolerant reaction to YMV disease whilst genotype 12 had mean tolerance reaction to YMV but that was not consistent across environment. Genotypes 7 and 9 had comparatively lower tolerance to YMV disease and were also not stable.

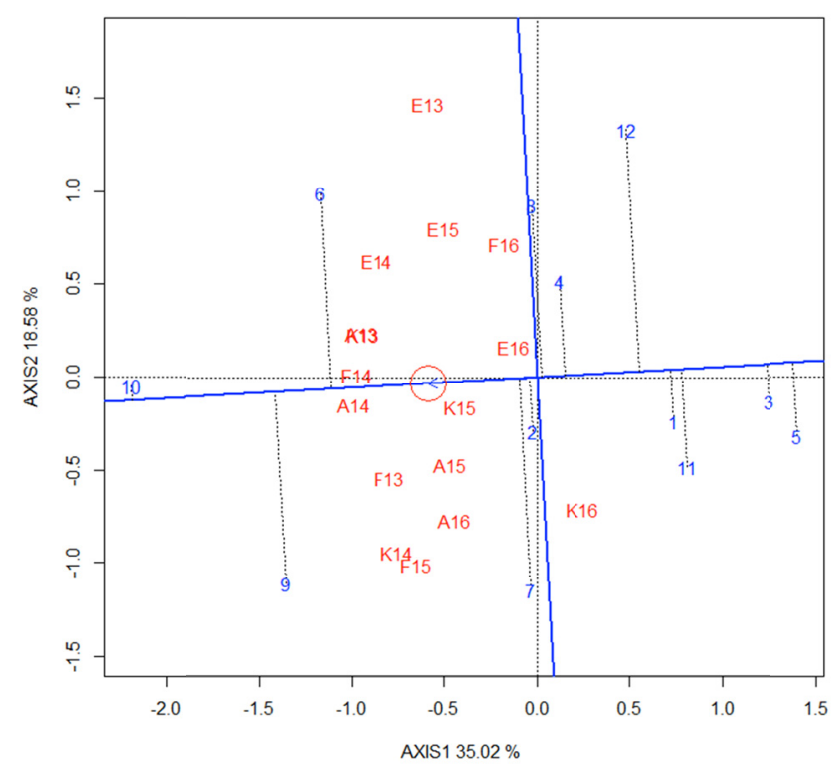

Figure 1. Mean and stability of YMV response of 12 D. rotundata genotypes in 16 environments 


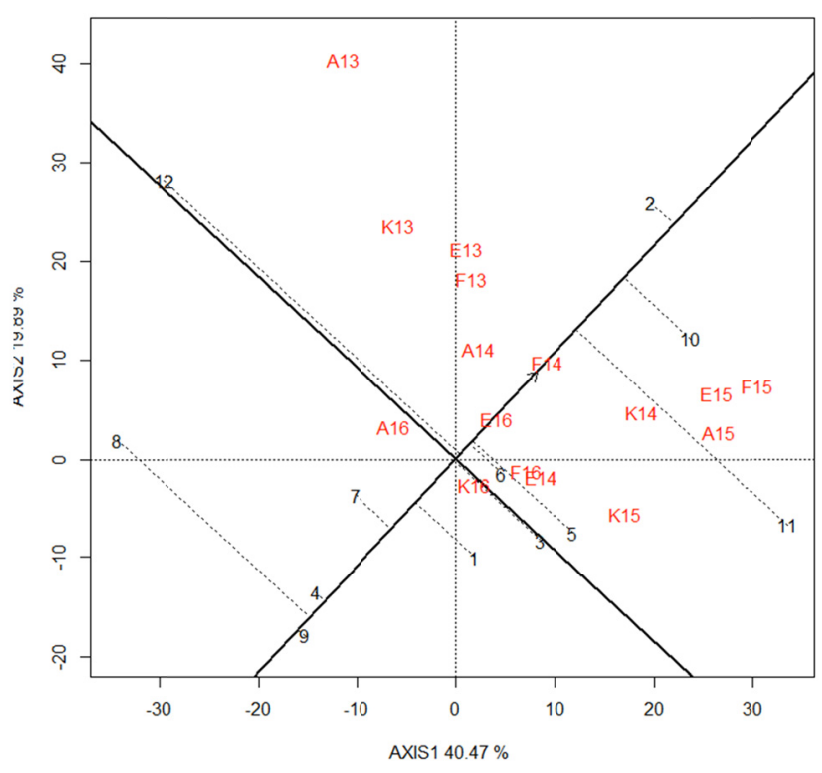

Figure 2. Mean and stability of yield of 12 D. rotundata genotypes in 16 environments

For yield biplots (Figure 2), partitioning of G + GE effects (GGE) showed that principal component 1 (PC1) and principal component 2 (PC2) accounted for $40.47 \%$ and $19.89 \%$ of GGE sum of squares, respectively and the two axes explained in a total of $60.36 \%$ of the GGE variation. Genotypes with PC1 values of $>0$ were considered high yielding and those with $\mathrm{PC} 1$ values of $<0$ lower yielding. $\mathrm{PC} 1$ scores of $>0$ therefore identifies the genotype of interest (i.e. adaptable or high yielding), while PC1 scores $<0$ discriminated the non-adaptable. PC2 on the other hand is related to stability or instability, and divides the biplot into two halves. Variable environmental effect was observed with respect yield of the genotypes in 16 environments. Most of the environments $(68 \%)$ had high potential for yielding except environments A16, A13 and K13, with A13 being the poorest environments where the lowest yield and unstable yield was recorded. The highest yield was obtained at environment F15, followed by E15 and A15, K14, K15, E14, F14, E16 and K16. Environments F16, E14, K14, E16, K15, E15, F15 and F14 were all high and stable yielding environments, with E16 and F14 being the most stable environments. Environment K16 was high yielding but unstable environment.

Genotypes 2, 3, 5, 6, 10 and 11 were all high tuber yielding with genotype 11 being the highest yielder followed by genotypes 10, 2, 5, 6 and 3. Genotypes 6, 5 and 10 were the higher yielding and stable genotypes. Genotype 4 had average tuber yield but very stable. Similarly genotypes 2 and 7 were just below average in tuber yield but very stable. Genotypes 8 and 12 were the poorest in terms of tuber yielding potential and stability. Genotype 11 was the highest yielding but very unstable genotype.

In assessing the relationship among environments based YMV disease scores and yield (Figures 3 and 4) respectively, the angle of the vectors of the environments were considered. In Figure 3, environment K16 had its angle of its vector at $180^{\circ}$ with environments E16, F16 and E13. Environment K15 was exactly $90^{\circ}$ with environments E16, F16 and E13. Environments F13, K15, A14, F14, A13, K13, E14, E15, E16, F16 and E13 have angle of $<90^{\circ}$ between the angles of their vectors. Environment A15, K14, F15 and A16 have angles of their vectors $>90^{\circ}$.

Similarly, the relationship amongst the environments based on yield (Figure 4), Environment K16 and K13 are $180^{\circ}$ apart. Environment K13 the most discriminative had its angle of vector $<90^{\circ}$ with environments E13, F13, F14, E15, A15 and F15. 


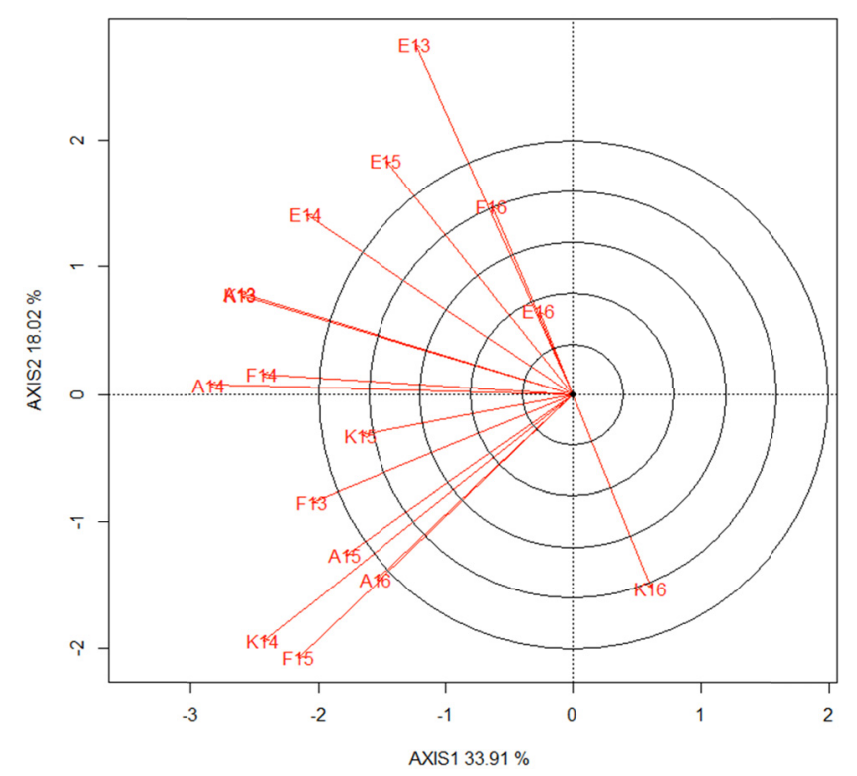

Figure 3. Relationship among environments based on YMV response of 12 D. rotundata genotypes in 16 environments

Environments A14, E16, E14, F16 and K15 had the angles of their vectors $>90^{\circ}$ away from K13. Environments K16 and K13 were 90o apart (positively correlated).

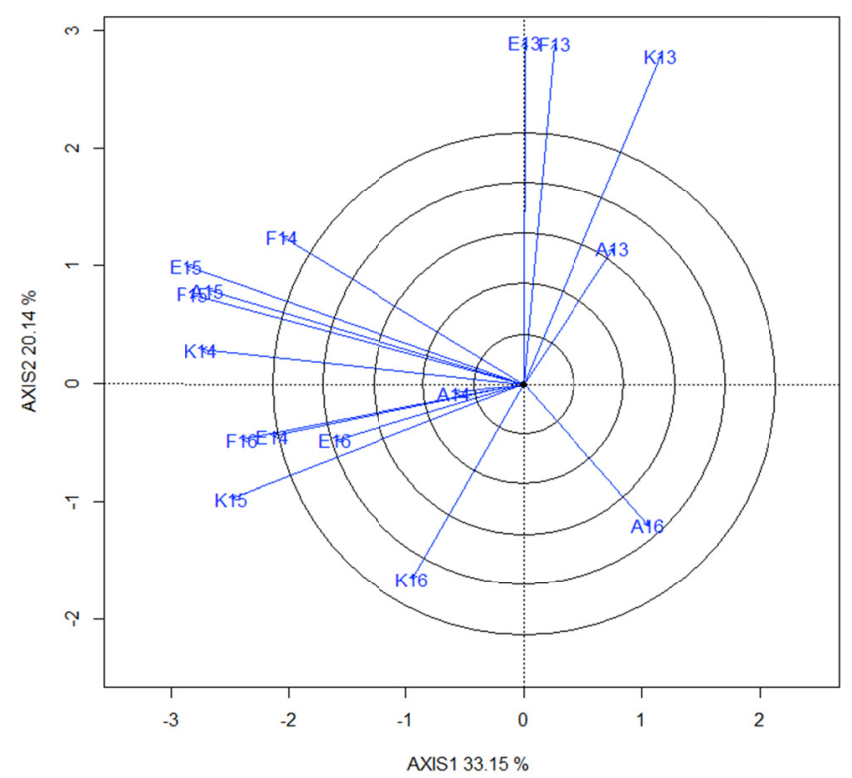

Figure 4. Relationship among environments based on yield of 12 D. rotundata genotypes in 16 environments 


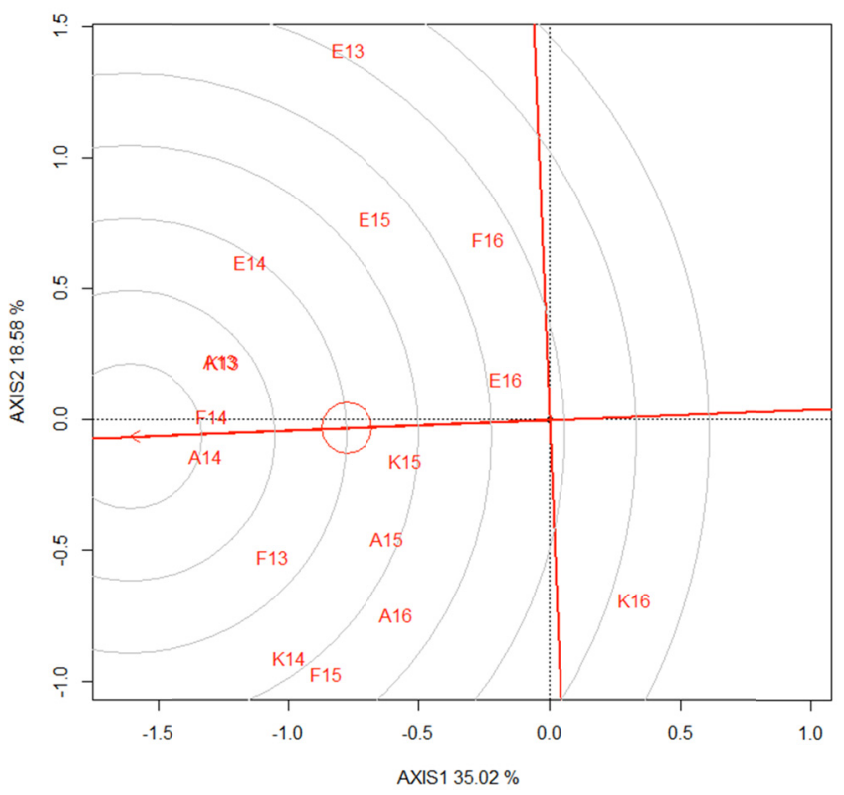

Figure 5. Ranking of environment based on YMV response of 12 D. rotundata genotypes in 16 environments

The ranking of the environments based on YMV tolerance can be assessed using the concept of ideal environment (Figure 5). The arrowed line points to the ideal environment for assessing YMV disease response. The closer the environment is to the centre of the concentric circle, the closer it is to the ideal environment. Environments A14 and F14 were the closest to the ideal environment followed by A13, K13, F13, K14, A15, $\mathrm{K} 15, \mathrm{~F} 15, \mathrm{~A} 16, \mathrm{E} 15, \mathrm{E} 16, \mathrm{~F} 16, \mathrm{E} 13$ and K16 in that order.

Similarly ranking of the environments based on yield of the $12 \mathrm{D}$. rotundata genotypes (Figure 6) showed that F15 was the most ideal environment for assessing the genotypes with respect to yield. This was followed by E15, A15, K14, E12, E13, F13, A14, E16, F16, E14, K15, K13, K16, A16 and A13 in that order.

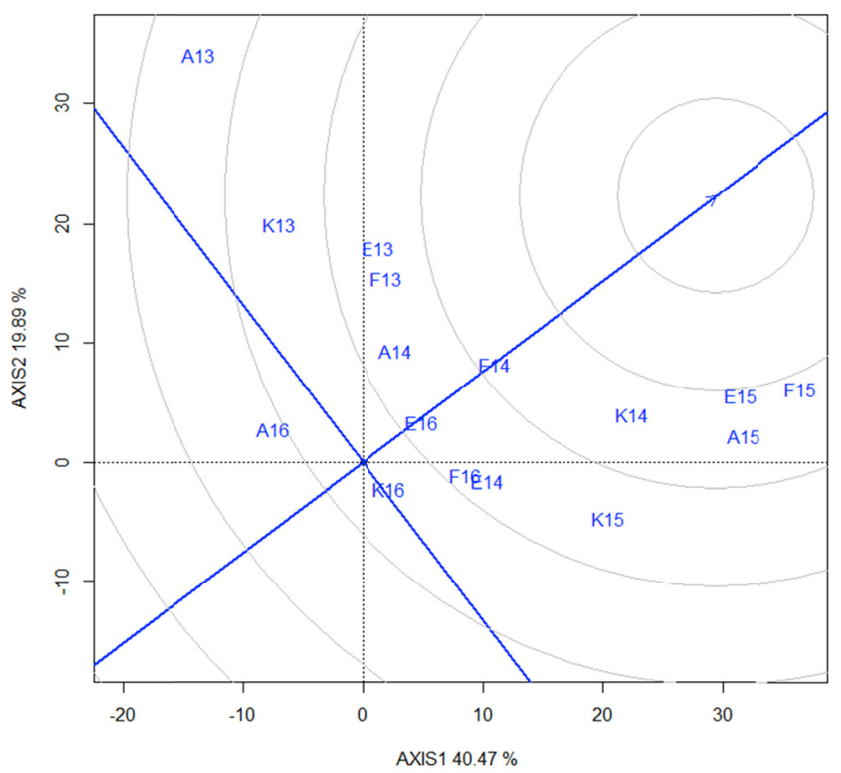

Figure 6. Ranking of environments based on Yield response of 12 D. rotundata genotypes in 16 environments 
To assess the discriminating power and representativeness of test environments, GGE biplots was drawn based on the YMV disease response and yield (Figures 7 and 8). The most discriminating environment with respect to response to YMV disease was E16 followed by K15, F16, A15, K16, A16, E15, F13, K14, F15, E14, A13, K13, F14 and A14. For yield, K16 was the most discriminative, followed by E16, F16, E14, A16, E14, A14, F14, F13, E13, K13, K15, K14, E15, A15 and F15 in that order. For YMV disease, F14 was the most representative with K16 as the least representative. For yield responses, E16 was the most representative and A13 least representative.

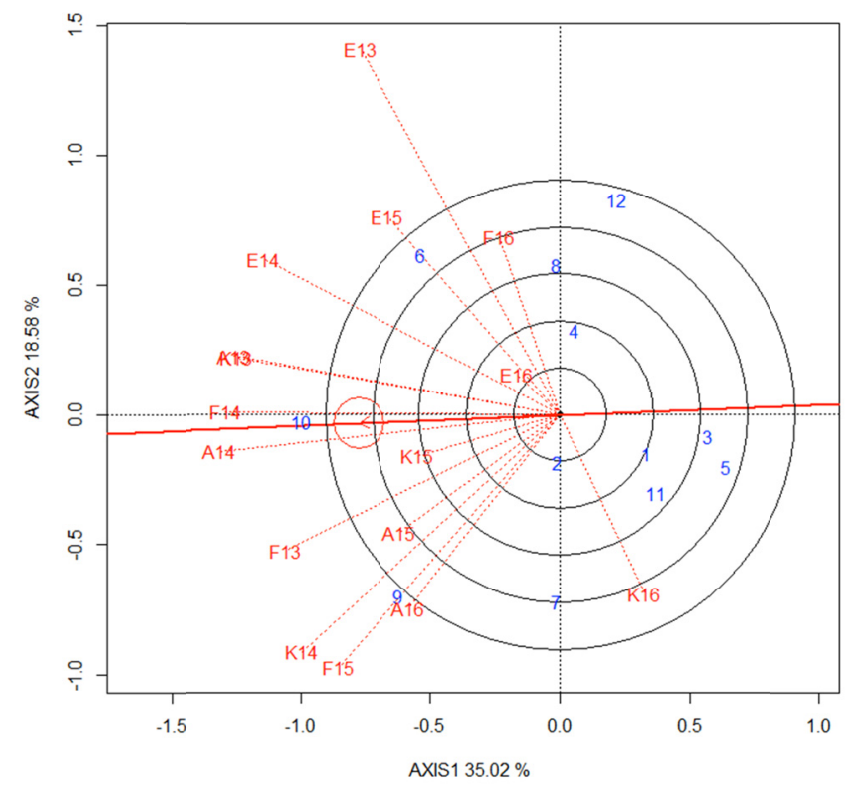

Figure 7. Discrimitiveness and representativeness of environment of YMV response of 12 D. rotundata genotypes in 16 environments

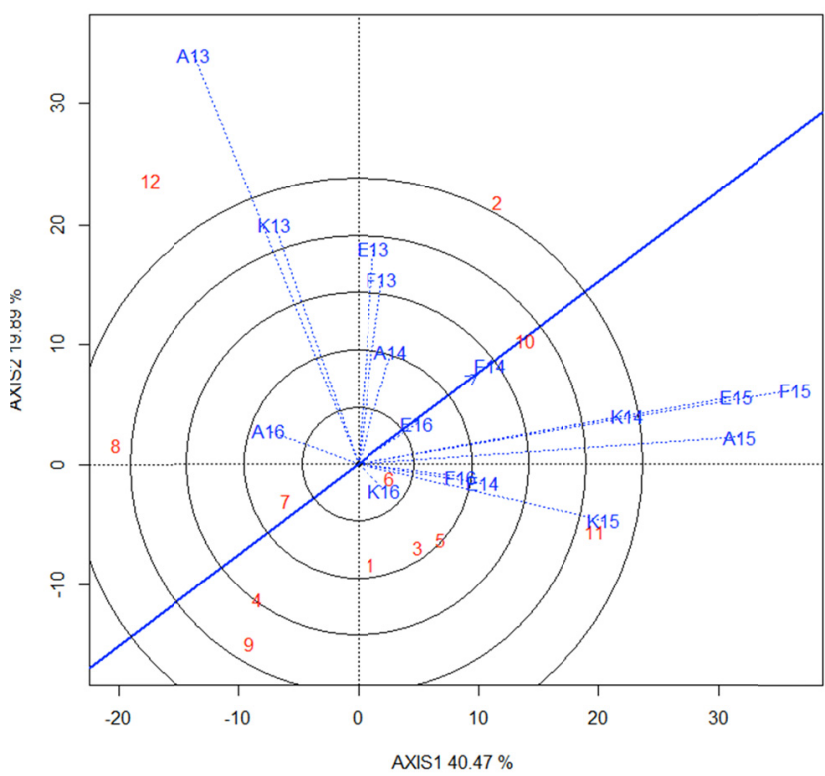

Figure 8. Discrimitiveness and representativeness of yield response of 12 D. rotundata genotypes in 16 environments

GGE biplots for an ideal genotype for YMV disease is presented with the average-environment coordination 
(AEC) view, which ranks genotypes relative to an ideal genotype (the center of the concentric circles) (Figure 9). This defines an "ideal genotype" as the one, which has the most tolerance to YMV disease in all environments. The arrowed line in the smallest concentric cycle points therefore to the ideal genotype. Hence the closer genotype is to the ideal, the better. The GGE biplots for identification of an ideal genotype for YMV disease identified genotype 10 as the ideal genotype followed by genotypes $9,6,2,7,3,4,12,1,11,3$ and 5 in that order.

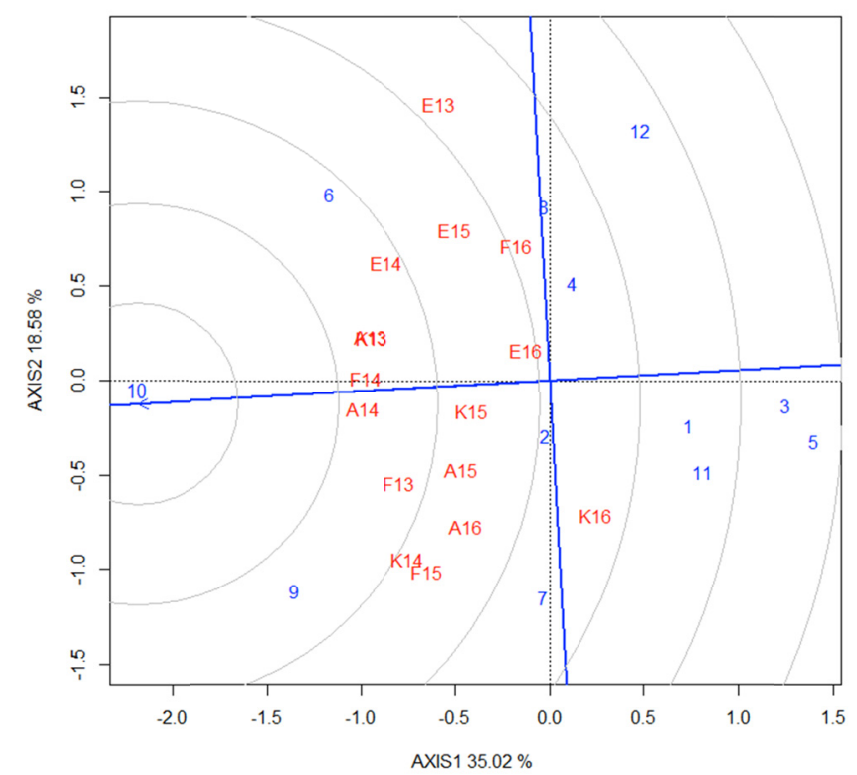

Figure 9. Ranking of genotypes based on YMV response of 12 D. rotundata genotypes in 16 environments

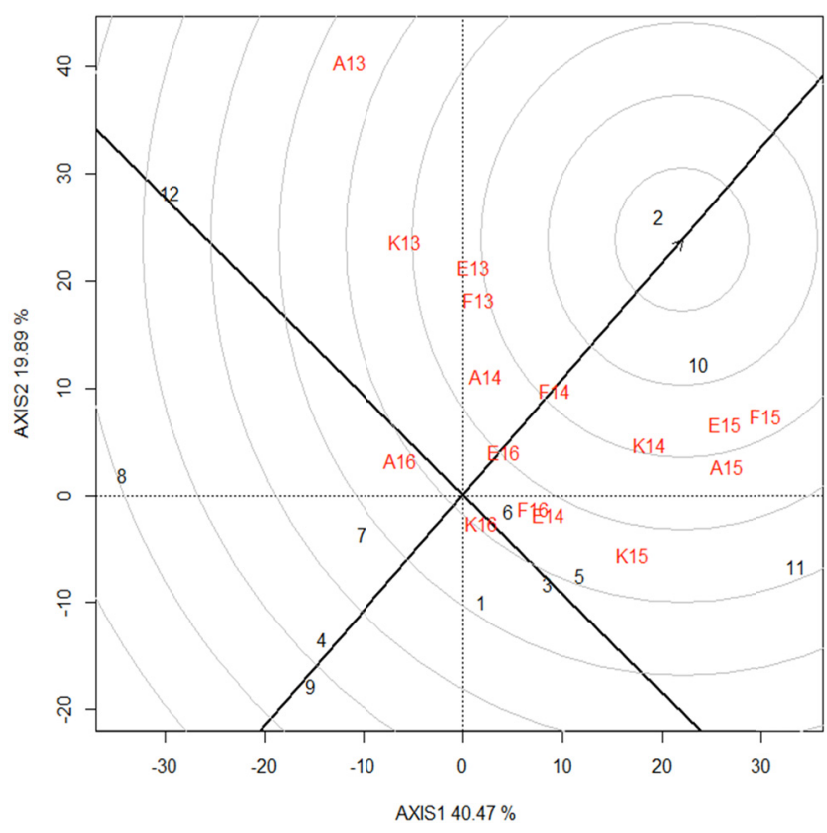

Figure 10. Ideal genotypes based on yield of 12 D. rotundata genotypes in 16 environments

Again the GGE biplots ranking of genotypes based on yield (Figure 10) identifies genotype 2 as the highest yielder and most stable, followed by genotypes $10,6,11,5,3,1,7.12,4,9$ and 8 in that order. 
The GGE biplot (Figure 11) depicts the genotypes that had the best tolerance to YMV of the genotypes in various environments. The convex-hull drawn from the biplot origin gave 6 sectors with genotypes 10, 6, 12, 5, 7 and 9 as vertex genotypes. Genotype 10 was the winner in the mega-environment encompassing 6 environments E14, A13, F14, A14, F13 and K15. Genotype 9 won in mega-environment of A15, A16, K14 and F15. In environment K16 genotype 7 was the most tolerant to YMV disease. Environments F16 had genotype 12 as the winner. Environments E13, E15, and E15 had no genotype as a winner, and no environment fell into the sectors with genotypes 12 and 5 as vertices with respect to YMV disease.

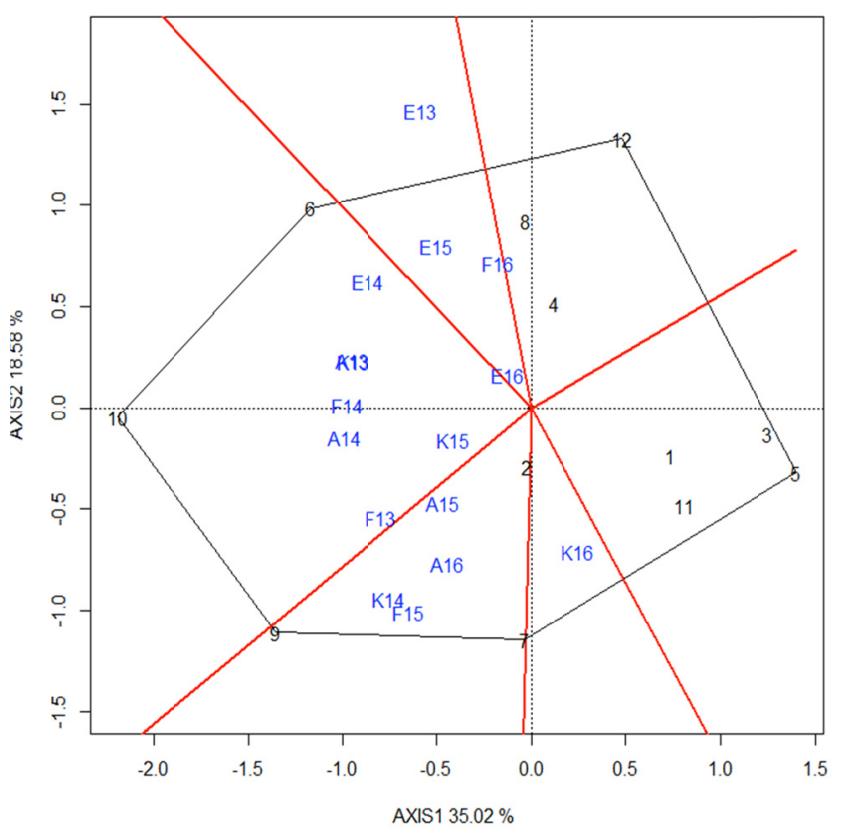

Figure 11. Which-won-where representation of 12 D. rotundata genotypes in 16 environments based on YMV response

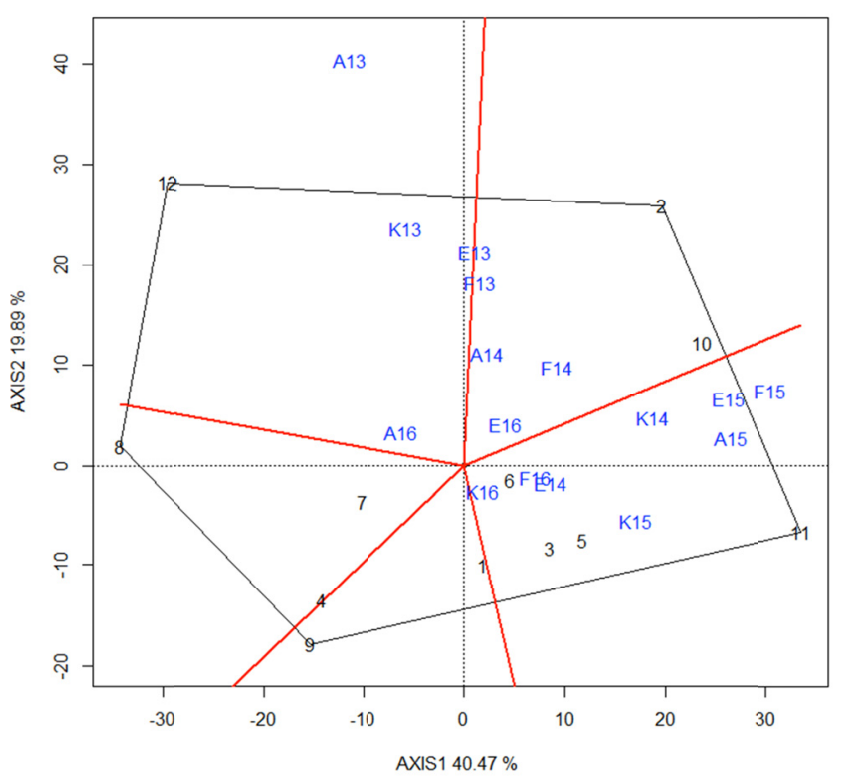

Figure 12. Which-won-where representation of 12 D. rotundata genotypes in 16 environments based on Yield response 
The GGE biplot (Figure 12) depicts the genotypes that had the best performance in each environment based on yield. The convex-hull drawn from the biplot origin gave 5 sectors with genotypes $12,2,11,9$, and 8 as the vertex genotypes. Genotype 12 was the vertex and the winning genotype in mega-environment comprising environments A13, K13, E13, F13 and A16. Genotype 2 was the winner in the next mega-environment A14, F14, and E16. Genotype 11 was the winner in mega-environment comprising K16, F16, E16, K15, A15, K14, E15 and F15, meaning that these cultivars are the best in these environments. No environment fell into sector with genotypes 8 and 9 as the vertices, indicating that these cultivars were not the best in any environment.

\section{Discussions}

The combined analysis of variance across environments (Table 4) showed highly significant $(\mathrm{P}<0.001)$ mean squares (MS) for YMV disease and yield. Effects from Genotype and environment showed highly significant MS reflected genotypic differences towards adaptation to different environments, suggesting that genotypes may be selected for adaptation to specific environments (Otoo \& Asiedu, 2009a, 2009b; Aina et al., 2009).

The highly significant variation observed among genotypes as indicated by the range of their mean performance, indicates the presence of sufficient genetic variability for the traits studied. The significant interaction between genotype and environment (GEI) for all the traits indicates that there is the need for multi-environment testing to identify good performers for specific environments.

The GGE biplot enabled visual comparison of the environments and genotypes studied and their interrelationships. The relative magnitude of the main effects and their interactions for YMV as a proportion of the total sum of squares showed that $32.7 \%$ of the severity score variation was attributed to Genotype (G), $7.7 \%$ to Environment (E) and $60 \%$ to GEI (Table 4). Similarly, the proportion of the total SS by various sources of variation of yield attributed to G, E and their interaction GEI were 19.1, 17.8 and $63.1 \%$ respectively. This is an indication of differential in YMV disease response as well as yield performance among yam genotypes across testing environments, which was due to the presence of GEI (Otoo \& Asiedu 2009a, 2009b).

\subsection{Mean Performance and Stability of Genotypes}

Genotypes should be evaluated based on both mean performance and stability across environments (Yan \& Rajcan, 2002). The single-arrowed line is the AEA, which points to higher mean tolerance across environments (Figure 1) and yield (Figure 2). The double-arrowed line is the AEC ordinate; it points to greater variability (poorer stability) in either direction (Yan \& Tinker 2006).

Results from mean and stability analysis shows that in the YMV disease scores ranged from 1.0 to 2.2, with a mean of 1.4; implying that none of the genotypes was susceptible (severity score > 2.5) (Table 5). Generally most of the genotypes were tolerant and stable. This was expected since the introductions from IITA were advanced lines developed for tolerance to YMV disease. The local checks are indigenous and have adapted to their environments. Similarly, tuber yield of the genotypes ranged from $36.4 \mathrm{t} / \mathrm{ha}$ (TDr07/02673) to $49.9 \mathrm{t} / \mathrm{ha}$ (Mankrong Pona) with a mean of $42.8 \mathrm{t} / \mathrm{ha}$. This was significantly high yield since the average yield for the Ghana is $15 \mathrm{t} / \mathrm{ha}$, and its comparable to the yield potential of improved released yam varieties of Mankrong Pona (70 t/ha), CRIKukrupa (50 t/ha) and CRIPona (42.0 t/ha), respectively.

\subsection{Relationships among Environments}

Generally, in assessing the relationship among environments (Figures 3 and 4), when the data is sufficiently approximated by the biplot, the cosine of the angle between the vectors of two environments approximates the correlation coefficients between them (Yan \& Rajcan, 2002). When the biplot explains a greater portion of the total variation, for example $>50 \%,(61.2 \%$ in this case) the angles exactly reflect the correlations among the testers. The cosine of the angle between the vectors of two environments therefore approximates the correlation between them. Two environments are positively correlated if the angle between their vectors is $<90$; two environments are negatively correlated if the angle between their vectors is $>90$; two environments are independent if the angle between them is 90 . Zero means regression coefficient $(r)=1,180$ means $r=-1$ and environments with longer vectors are more discriminative of the entries; those with short vectors are less discriminative; those located at the biplot origin are not discriminative at all. The cosine of the angle between the vectors of two environments therefore approximates the correlation between them.

The environment K16 was negatively correlated to E16, F16 and E13. K15 was also positively correlated E16, F16 and E13. This suggests that similar location can give contradicting relationships in different years, year being the distinguishing factor in this instant. This gives credence to need to conduct multi-locational trials in space and time in order to determine the best genotypes for release as varieties. In Fumesua, $75 \%$ of its occurrence had angle of its vectors greater than $90 \%$ with the other environments suggesting that the Fumesua 
(Forest zone) is different from the other environments and must be considered unique and necessary for evaluation of the genotypes with respect to YMV and yield assessment. All other environments, which were all in the Forest-Savannah Transition agroecology, could be considered as another group of necessary environments for assessment of both YMV disease and yield.

The soils of the forest agroecology are mostly Forest Ochrosols. They are red, brown and yellow-brown, well to imperfectly drained soils occurring on summits, upper, middle and lower slopes. Such soils have a marked concentration of organic matter in the upper topsoil (A horizon) with strongly leached lower horizons (CEPA, 2000).

The soils of the Forest belts of Ghana are easily distinguished from those of the Savannah belts by the greater accumulation of organic matter in the surface horizon resulting from the more abundant leaf-fall under Forest vegetation and the slower rate at which humus is oxidised. The soils of the Savannah belts are on the other hand, generally lower in organic matter within the surface horizon due to the fact that grass is the dominant vegetation. In addition, over extensive areas, such soils have unfavourable moisture relationships due mainly to the fact that rainfall is less reliable in occurrence than in the Forest belts (CEPA, 2000).

In the FST agroecologies, substantial areas of level to near-level relief within the Savannah patches are covered by deep, to very deep, non-gravelly, sandy clay Savannah Ochrosols, mainly Ejura and Damongo series. Though the soils are quite low in inherent fertility and subject to erosion and droughts, they are considered to be well suited to extensive mechanised cultivation of maize, guinea corn, sunflower, cashew nuts, yams, tobacco, soybeans, groundnuts and fibre crops such as cotton, urena lobata and kenaf. However, for increased and sustained crop production, there will be the need to improve upon the fertility status of the soils through manuring and the application of commercial fertilisers, especially a suitable compound of NPKMg (CEPA, 2000).

\subsection{Choice of Genotypes}

An ideal genotype should have the highest mean performance and be absolutely stable (i.e. perform the best in all environments). Additionally, it should have good disease tolerance as well as good culinary characteristics. Such an ideal genotype is defined by having the greatest vector length of the high yielding genotypes and with zero GEI as represented by an arrow pointing to it (Figures 9 and 10). Although such an ideal genotype may not exist in reality, it can be used as a reference for genotype evaluation. A genotype is more desirable if it is located closer to the ideal genotype. The cosine of the angle between the vectors of two genotypes also measures their similarity or dissimilarity in response to their interaction with the environments (Yan \& Tinker, 2006). Using the ideal genotype as the center, concentric circles were drawn to help visualize the distance between each genotype and the ideal genotype. For YMV disease assessment, Figure 9 revealed that genotype 10 was the closest to the ideal genotype followed by genotypes $9,6,2,7,3,4,12,1,11,3$ and 5 in that order. For yield response, genotype 2 was the highest yielder and most stable, followed by genotypes $10,6,11,5,3,1,7.12,4,9$ and 8 in that order. In choosing the genotypes for release based on tolerance YMV disease and yield, genotypes 2, 3, 4, 5, $6,7,8,9,10,11$ and 12 may all be considered. Genotype 10 had high and stable tolerance to YMV disease, but genotypes 9 had good but unstable response to YMV disease and were comparatively low yielders. In terms of yield, Mankrong Pona was the most stable and high yielding (closest to the ideal genotype) followed by TDr95/19177. Genotypes TDr00/02472, TDr00/00539 and TDr98/00933 were desirable genotypes for released as varieties, and since Mankrong Pona has already been released in Ghana and TDr95/19177 has also been released in Nigeria (by ECOWAS protocol, usable in Ghana), only genotypes TDr00/02472, TDr00/00539 and $\mathrm{TDr} 98 / 00933$ are available for released as varieties.

\section{4 "Which-Won-Where" Analysis}

In "which-won-where" analysis of the GGE biplot analysis, a polygon is first drawn on genotypes that are located away from the biplot origin so that all other genotypes are contained in the polygon. Perpendicular lines are then drawn, starting from the biplot origin, to each side of the polygon (Figures 11 and 12). These perpendicular lines divide the biplot into sectors, and the winning genotype for each sector is the one located on the respective vertex.

Genotypes 10, 9, 7, 12, were winners in various mega-environments with respect to YMV disease tolerance. Similarly, genotypes $12,2,11,9$, and 8 were winners in various mega-environments with respect to yield response. Since the environments encompassed similar locations at various years, it pre-supposes that these genotypes could all be used in all the locations.

\subsection{Ideal Test Environments for Selecting High Mean Performance Genotypes}

The ideal test environment should be most discriminating (informative) and most representative. Figures 7 and 8 
define an "ideal test environment" for 12 D. rotundata genotypes in 16 environments based on YMV disease tolerance and yield respectively.

\subsection{Discriminativeness and Representativeness of Test Environments}

The lines that connect the test environments to the biplot origin are called environment vectors. The length of the vectors approximates the standard deviation within the respective environments, which is a measure of the discriminating ability of the environments (Yan, 2005).

For response to YMV disease (Figure 7), the most discriminating environment was E16 followed by K15, F16, A15, K16, A16, E15, F13, K14, F15, E14, A13, K13, F14 and A14. For yield, K16 was the most discriminative, followed by E16, F16, E14, A16, E14, A14, F14, F13, E13, K13, K15, K14, E15, A15 and F15 in that order. Again, Ejura locations were the most represented in the top 5 discriminating environments for yield. With resource limiting therefore, Ejura could be used as test site for evaluating for both YMV disease tolerance and yield.

\subsection{Representativeness of the Test Environments}

The representativeness of the test environment can be assessed using "Average-Environment Axis" (AEA, or average-tester-axis,) view of the GGE biplot (Yan, 2001). The average environment has the average coordinates of all test environments, and AEA is the line that passes through the average environment and the biplot origin. A test environment that has a smaller angle with the AEA is more representative of the target environment. For YMV disease, Fumesua was the most representative with Kintampo as the least representative. For yield responses, E16 was the most representative and A13 least representative.

\section{Conclusions}

The need for assessing spatial and seasonal genotype and environment interaction in yams was confirmed, with Ejura and Fumesua as the most discriminating and most representative for YMV respectively. In terms of yield, Kintampo environment was the most discriminating and Fumesua and Atebubu were identified as the closest to ideal environment for evaluating yield. All the four locations used for the study are highly relevant for research and development of yams.

The genotypes assessed also had good tolerance to YMV disease and high yields. Genotypes TDr07/00362 and TDr07/02673 though had high tolerance to YMV disease, were low yielders are therefore candidates for improving other genotypes in future. In terms of yield, Mankrong Pona was the most stable and high yielding (closest to the ideal genotype) followed by TDr95/19177 with genotypes TDr00/02472, TDr00/00539 and TDr98/00933 following in that order. Since Mankrong Pona has already been released in Ghana and TDr95/19177 has also been released in Nigeria (by ECOWAS protocol, usable in Ghana), only genotypes TDr00/02472, TDr00/00539 and TDr98/00933 are available for released as varieties.

\section{References}

Aina, O. O., Dixon, A. G. O., Ilona, P., \& Akinrinde, E. (2009). G $\times$ E interaction effects on yield and yield components in the Savanna region of Nigeria. Afr. J. Biotechnol., 8(19), 4933-4945.

Akinyele, B. O., \& Osekita, O. S. (2011). Genotype $\times$ Environment Interaction in NH47-4 Variety of Okra-Abelmoschus esculentus (Linn.) Moench. Int. J. Gene. Mol. Biol., 3(4), 55-59.

Asiamah, R. D., \& Adu, S. V. (1992). Soils of the Ayensu-Densu Basin, Central, Eastern and Greater Accra Regions of Ghana. Soil Research Institute Memoir No. 9, Council for Scientific and Industrial Research (CSIR).

Asiamah, R. D., Mensah, C. A., \& Nyantakyi, P. O. (1993). Report of the detailed soil survey and land evaluation of Wenchi Agricultural Research Station. Technical Report No. 171. Brong Ahafo Region, Ghana.

CEPA (Centre for Policy Analysis). (2000). Soil Classification in Ghana. Ghana Selected Economic Issues, 3 , $1-33$.

Gabriel, K. R. (1971). The biplot graphic display of matrices with application to principal component analysis. Biometrika, 58, 453-467. https://doi.org/10.1093/biomet/58.3.453

Malosetti, M., Ribaut, J.-M., \& van Eeuwijk, F. A. (2013). The statistical analysis of multi-environment data: Modeling genotype-by-environment interaction and its genetic basis. Front. Physiol., 4, 44. https://doi.org/ 10.3389/fphys. 2013.00044

Otoo, E., \& Asiedu, R. (2009a). The Performance Profile of Dioscorea rotundata Cultivar "Dorban" Genotypes in Ghana Using GGE Biplot Analysis. Journal of Food, Agriculture \& Environment, 7(1), 150-155. 
Otoo, E., \& Asiedu, R. (2009b). GGE Biplot Analysis of Dioscorea rotundata Cultivar "Tela" Genotypes in Ghana. Journal of Food, Agriculture \& Environment, 7(1), 134-139.

Sakin, M. A., Akincl, C., Duzdemir, O., \& Donmez, E. (2011). Assessment of Genotype $\times$ Environment Interaction on Yield and Yield Components of Durum Wheat Genotypes by Multivariate Analyses. Afr. $J$. Biotechnol., 10(15), 2875-2885. https://doi.org/10.5897/AJB10.2197

Ssemakula, G., \& Dixon, A. (2007). Genotype $\times$ Environment Interaction, Stability and Agronomic Performance of Carotenoid-rich Cassava Clones. Sci. Res. Essay, 2(9), 390-399.

Yan, W. (2001). TGGE biplot-A Windows application for graphical analysis of multi-environment trial data and other types of two-way data. Agron. J., 93(5), 1111-1118. https://doi.org/10.2134/agronj2001.9351111x

Yan, W. (2005). Use of biplot analysis in crop breeding. Proceedings of the Eastern Wheat Workers and Southern Small Grain Workers Conference, May 9-12, 2005 (pp. 7-30). Bowling Green, KY.

Yan, W., \& Kang, M. S. (2003). GGE Biplot Analysis: A Graphical Tool for Breeders, Geneticists, and Agronomists (p. 271). CRC Press, Boca Raton, FL, USA.

Yan, W., \& Rajcan, I. (2002). Biplot analysis of test sites and trait relations of soybean in Ontario. Crop Sci., 42, 11-20. https://doi.org/10.2135/cropsci2002.1100

Yan, W., \& Tinker, N. A. (2006). Biplot analysis of multi-environment trial data: Principles and applications. Can. J. Plant Sci., 86, 623-645. https://doi.org/10.4141/P05-169

Yan, W., Hunt, L. A., Sheng, Q., \& Szlavnics, Z. (2000). Cultivar Evaluation and Mega-environment Investigation based on the GGE Biplot. Crop Sci., 40, 597-605. https://doi.org/10.2135/cropsci2000. $403597 x$

\section{Copyrights}

Copyright for this article is retained by the author(s), with first publication rights granted to the journal.

This is an open-access article distributed under the terms and conditions of the Creative Commons Attribution license (http://creativecommons.org/licenses/by/4.0/). 